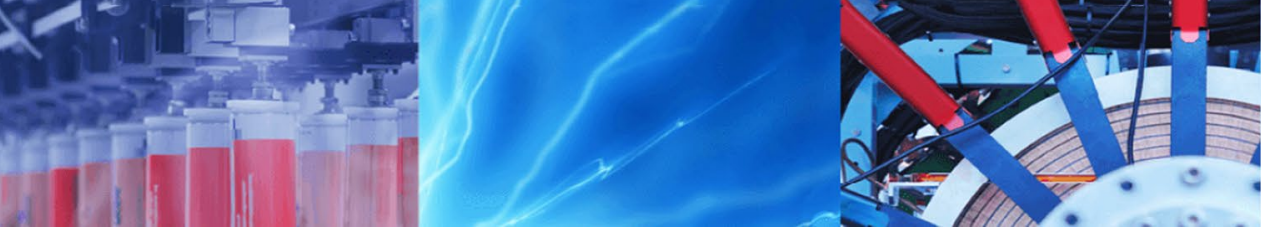

Research Article

\title{
Preliminary interpretation of isostatic residual gravity anomalies within the central portion of the Equatorial Atlantic African region
}

\author{
Oluwatimilehin Benjamin Balogun ${ }^{1}$
}

(c) Springer Nature Switzerland AG 2019

\begin{abstract}
Airy's isostatic residual gravity anomaly map and profiles were interpreted for the central portion of the Equatorial Atlantic African region with a view to understanding the lithospheric dynamics, hence imminent vertical crustal movements and thus predict the future outlook of evolving landscape within the study area. In order to compute the isostatic residual gravity anomaly, the AIRYROOT algorithm of the United States Geological Survey was used and isostatically overcompensated, undercompensated and completely compensated portions were identified on the isostatic residual gravity anomaly map and profiles. The Airy's isostatic residual gravity anomaly map showed three distinct parts which were the oceanic south-western part characterised by negative isostatic residual gravity anomaly values ( -11 to $-200 \mathrm{mGal})$, the volcanic eastern and extreme northcentral parts characterised by positive isostatic residual gravity anomaly values $(+10$ to $+90 \mathrm{mGal}$ ) and the central part having a network of sedimentary basins, characterised by isostatic residual gravity anomaly values that approach zero $(-10$ to $+9 \mathrm{mGal})$. It was discovered that the oceanic south-western part was isostatically overcompensated, the uplifted eastern part and the Younger Granite Province of the extreme northcentral part were undercompensated and the central part consisting of the Niger Delta, Benue Trough and the Mid-Niger (Nupe) Trough was completely compensated. It was consequently predicted that vertical uplift is imminent in the isostatically overcompensated oceanic region while subsidence is expected over the region of the eastern upland and the Younger Granite Province which were associated with isostatic undercompensation. The sedimentary basins within the study area are expected to remain stable.
\end{abstract}

Keywords Isostatic residual gravity anomaly · Vertical crustal movement · Isostatically overcompensated · Isostatically undercompensated $\cdot$ Complete compensation

\section{Introduction}

The earth's lithosphere, consisting of the crust and uppermost part of the upper mantle, is dynamic and tends towards a state of hydrostatic equilibrium known as isostatic equilibrium which could be attained locally or regionally $[1,2]$. As understood from the concept of Airy-Heiskanen and Pratt-Hayford models of isostasy, the lighter crust floats freely on the underlying, viscous but denser mantle. Volcanoes, sediments and ice sheets constitute loads that can be imposed on the crust. When the crust is loaded, the underlying mantle responds to the crustal loading (or unloading in case of erosion of crustal loads) by vertical column adjustments. This lithospheric response to crustal loading and unloading is interpreted as isostatic adjustment.

Surface processes and isostatic response are known to be related [2]. Isostatic compensation is often incomplete and usually results in vertical crustal movements which could be of great significance in landscape evolution. Mountains are subject to erosion, which can disturb isostatic compensation [3]. If the eroded mountains are

$\bowtie$ Oluwatimilehin Benjamin Balogun, balogun.timilehin2015@gmail.com | Department of Geology, Obafemi Awolowo University, Ile-Ife, Nigeria.

SN Applied Sciences (2019) 1:495 | https://doi.org/10.1007/s42452-019-0440-5

Received: 20 December 2018 / Accepted: 2 April 2019 / Published online: 27 April 2019 
no longer high enough to justify their deep root zones, the topography then becomes isostatically overcompensated, buoyancy forces are created and this results in vertical uplift of the region, a phenomenon which is usually associated with positive topographic movement noticeable from the leveling survey of such area. Conversely, when a topographic root is too small compared to the topography it supports, vertical subsidence occurs. When compared with leveling survey, this usually corresponds with negative movement (i.e. subsidence).

The ultimate goal of isostatic adjustments is the attainment of complete isostatic compensation, hence, stability within the lithosphere. As earthquakes, volcanic activities, mountain ranges, ocean trenches (or subduction zones) as well as many other tectonic processes and features which are capable of disrupting the hydrostatic equilibrium of the earth's asthenosphere are created from tectonic plates movements and interactions, the earth's outer layers naturally try to readjust towards an equilibrium state which is known as state of complete isostatic compensation and this equilibrium quest of the earth redistributes surface and subsurface lithospheric loads and thus contributes significantly to the shaping and the future outlook of the crust.

From the current isostatic condition within the central portion of the Equatorial Atlantic African region, this research work attempted to predict the imminent vertical crustal movement and the evolving landscape outlook in terms of regions that are likely to be uplifted and those that will undergo subsidence.

In essence, this research work focuses on identifying isostatically overcompensated, undercompensated and completely compensated regions within the study area and relates them with vertical crustal movements and lithospheric geologic structures and phenomena.

The study area in this research work is designated as "the central portion of the Equatorial Atlantic African region". It spans between the equator $\left(0^{\circ} \mathrm{N}\right)$ to latitude $10.0^{\circ} \mathrm{N}$ and between longitudes $3.0^{\circ} \mathrm{E}$ and $15.0^{\circ} \mathrm{E}$ (Fig. 1).

The area has continental and oceanic regions. The elevation ranged from $-4200 \mathrm{~m}$ (at the extreme southwestern end) to $4000 \mathrm{~m}$ (at Mt. Cameroon). The eastern region consists of plateau, the south-western region is the oceanic section, the central region is a coastal sedimentary

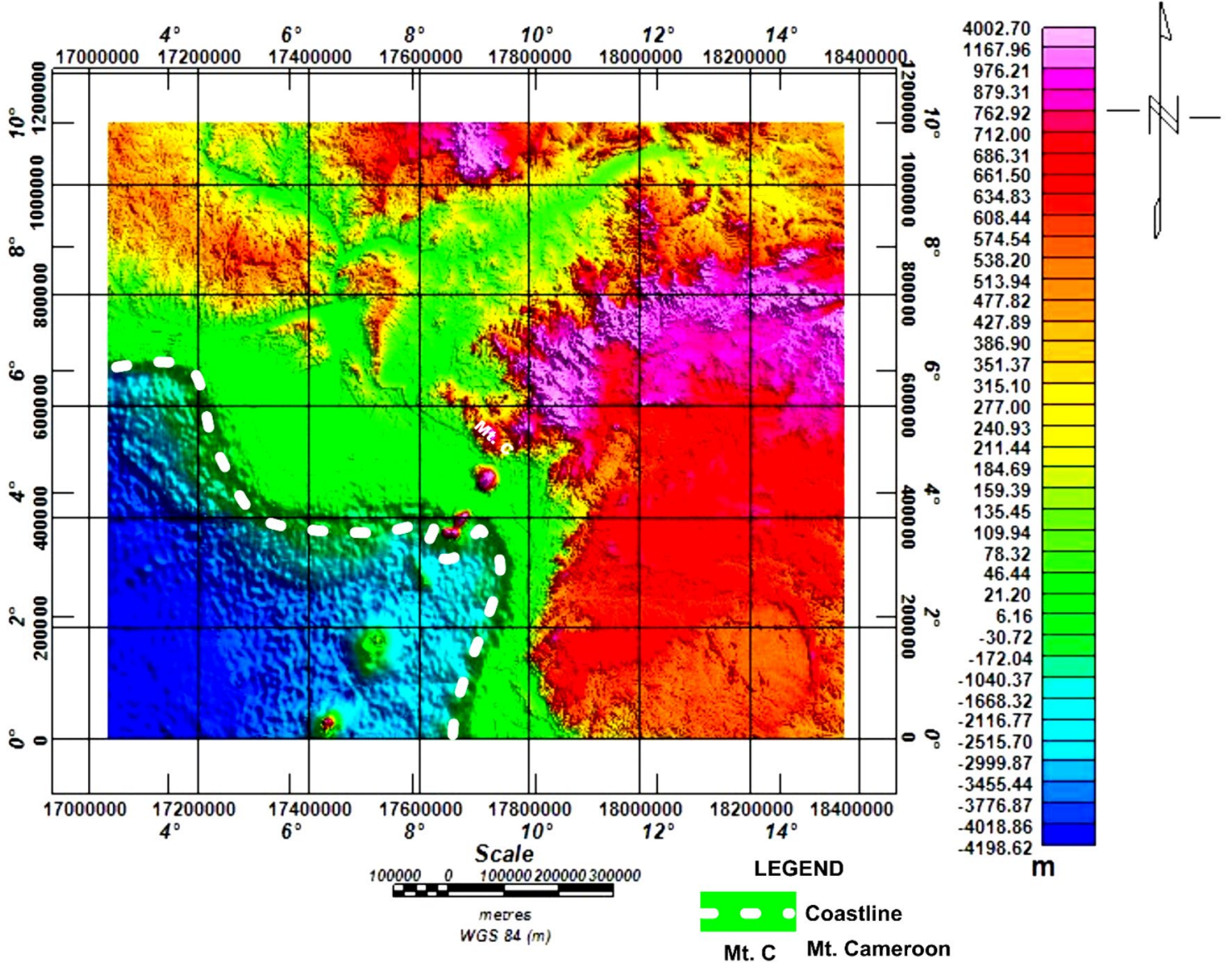

Fig. 1 Map of the study area

SN Applied Sciences 
lowland which is approximately at sea level, and the northwestern and the northcentral areas are areas of moderate and high elevation, respectively. The mean elevation for the mountains and plateau found in the region is about 1 km (Fig. 1).

\subsection{Tectonic settings and classic geology of the study area}

Major continental regions covered by this study include the Niger Delta, the Niger Basin, the Benue Trough, the Nigerian Shield (south-western basement complex and part of the north central basement complex of Nigeria), the Cameroon Volcanic Line (CVL) and the Adamawa Uplift (Cameroon), the Central African Shear Zone (Ngaoundere Rift) in Cameroon and the Gabon-Cameroon Shield. Figure 2 is the classic geological map of the study area on which some major tectonic provinces are indicated.

The study area is characterised by intraplate volcanism such as that along the Cameroon Volcanic Line (CVL). The region is tectonically complex, consisting of cratons, mobile belts, shear zones and regions of active magmatism. Various models which include reactivation of ancient suture zones, lithospheric thinning by mantle plumes and edge-driven mantle convection have been proposed to explain the process of tectonic evolution in the study area [4]. Other than the CVL, a major tectonic structure in the study area is the Benue Trough which is a Mesozoic rift basin that starts from the coast of the Gulf of Guinea and extends transversely as a deep furrow within the Nigerian Shield. It forms part of the west African Mesozoic bifurcating rift system which connects other continental rifts in the interior of West African republics of Chad and Niger $[5,6]$. It is believed to have a length of about $1000 \mathrm{~km}$ and a maximum width of about $300 \mathrm{~km} \mathrm{[7]} \mathrm{and} \mathrm{has} \mathrm{been} \mathrm{con-}$ sidered to be an aulacogen [8-10].

According to Osazuwa [11], three notable events had happened in the Benue Trough which were rifting caused by the separation of South America from Africa, volcanism marked by the axial gravity high along the trough due to the presence of volcanic rocks under the sediments and folding (or compression) represented by gravity low flanking the axial gravity high.

The Niger Basin (Nupe Basin) is another prominent intracratonic basin within the study area. It is bounded in the north-east and south-west by the basement complex, while it merges with Anambra and Sokoto basins in sedimentary fill comprising post-orogenic molasse facies and a few thin unfolded marine sediments [12]. Based on interpretation of preliminary gravity data, while Ojo and Ajakaiye [13] favoured the Isostatic Subsidence Hypothesis, they concluded that a rifting origin is, however, still a possibility because the gravity effect of the shallow structural features may have masked the effect of deeper features.

Found in the study area also is the Nigerian Shield consisting of the Nigerian basement complex which is situated within a Pan-African mobile zone extending between the West African Craton in the west and the Congo Craton in the south-east. Nigeria lies in the central part of the Gondwana portion of the Pangea Supercontinent and remained a fairly resistant region to denudation [14]. The Nigerian Shield is part of the ancient rocks of the African shield.

The Adamawa Uplift falls within the study area as well. The Adamawa Uplift is a volcanic dome in central Cameroon formed during the Tertiary together with other African volcanic uplifts such as the East African Plateau, and is underlain by Precambrian basement rocks, remobilised by the Pan-African episode (600-500 Ma) and uplifted $(1 \mathrm{~km})$ relative to the surrounding area. These rocks, mainly schists, and gneisses intruded by granites and diorites, are cut by faults of the Central African Shear Zone (CASZ) [15]. The Adamawa Uplift comprises of the Adamawa Plateau, the Oku Massif, Mount Bambouto and the Manengouba Mountain. The study area also comprises of the Central African Shear Zone (CASZ) and the Gabon-Cameroon Shield. The Central African Shear Zone is a megashear zone in Africa extending over about $200 \mathrm{~km}$ from Sudan to Cameroon [16]. It was believed to be formed during the Pan-African cycle $(600 \pm 100 \mathrm{Ma})$ during which important tectonic movements occurred giving rise to the megashear zones in Africa [16].

\section{Materials and methods}

\subsection{Data description}

The dataset used for this study is the combination of terrestrial gravity data and satellite altimetry gravity dataset consisting of global $1 \times 1$ min grid Bouguer anomaly and topographic-bathymetric data compiled from GeoSat (ERS-1), CryoSat-2 and Jason-1 surveys made available by Scripps Institution of Oceanography, University of California, San Diego, USA, and GETECH Africa Gravity Project, Leeds, UK.

The data have a resolution of $1 \times 1$ min grid. This in land units equals to $1859 \mathrm{~m}$ by $1841 \mathrm{~m}$ (i.e. $1.86 \mathrm{~km}$ by $1.84 \mathrm{~km}$ ). The implication of this is that this dataset can at best only be used for regional studies.

The $1 \times 1$ min grid free-air gravity and topographicbathymetric data were acquired in degrees but were converted to World Geodetic System (WGS)-metre coordinate system for easy location of features and distances. The Universal Transverse Mercator (UTM) coordinate system was not adopted because of its zonal dependency. Instead, a 


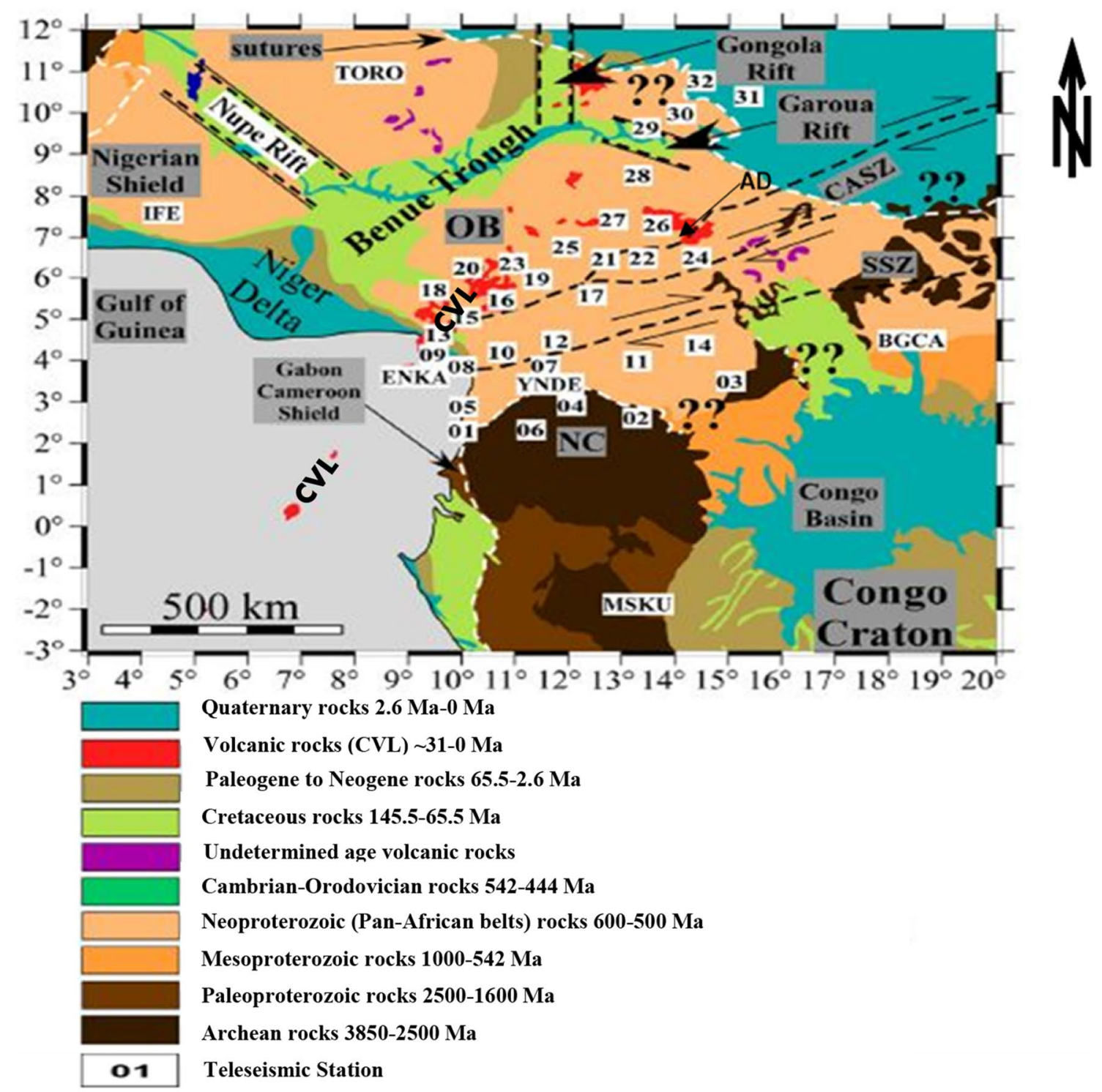

CASZ - Central African Shear Zone

SSZ - Sanaga Shear Zone

OB - Oubanguide Complex

$\mathrm{AD}$ - Adamawa Uplift

NC - Ntem Complex

CVL - Cameroon Volcanic Line

Fig. 2 Geologic map of the study area (Modified after [4])

more uniform WGS-m coordinate system which is more suited for regional studies was adopted.

\subsection{The isostatic residual gravity anomaly}

Isostatic correction can be likened to removing the topography-induced regional gravity field so that intracrustal density contrasts are enhanced and any form of correlation of the Bouguer anomaly with the topography is significantly suppressed. Basically, when isostatic correction is carried out on Bouguer gravity anomaly, the result is the isostatic gravity anomaly $\left(\Delta g_{i}\right)$ and this is done by subtracting the computed anomaly $\left(\Delta g_{R}\right)$ of the root zone estimated from the topography from the Bouguer gravity anomaly $\left(\Delta g_{\mathrm{B}}\right)$ such that: 
$\Delta g_{\mathrm{i}}=\Delta g_{\mathrm{B}}-g_{\text {Root }}$

where $\Delta g_{\mathrm{i}}$ is the isostatic gravity anomaly, $\Delta g_{\mathrm{B}}$ is the Bouguer Anomaly and $g_{\text {Root }}$ is the computed anomaly of the root zone [3].

For geodynamics, tectonics studies and analysis of topographic structures, however, a variant of the isostatic gravity anomaly known as the "isostatic residual gravity anomaly" is preferred as it enhances intracrustal density contrasts better [17]. This variant is also interpreted in the same manner as the basic isostatic gravity anomaly. Conventionally, it is given as follows:

$\Delta g_{\text {Isos_Res }}=g_{\text {obs }}+g_{\mathrm{fa}}-g_{\mathrm{bc}}+g_{\mathrm{t}}-g_{\text {Isos_reg. }}-g_{\mathrm{o}}$

$=\Delta g_{\mathrm{B}}-g_{\text {Isos_reg }}$

where $\Delta g_{\text {Isos_Res }}$ is the isostatic residual gravity anomaly; $g_{\mathrm{obs}}$ is observed gravity; $g_{\mathrm{fa}}$ is free-air correction; $g_{\mathrm{bc}}$ is Bouguer correction; $g_{\mathrm{t}}$ is terrain correction; $g_{\text {Isos_reg. }}$. is gravitational field from $166.7 \mathrm{~km}$ out to infinity; $\Delta g_{\mathrm{B}}$ is Bouguer Anomaly and $g_{\mathrm{o}}$ is Theoretical gravity (Fig. 3).

In order to compute the isostatic residual gravity anomaly, the AIRYROOT [18] approach was used. This approach employs the algorithm of Parker [19], which uses a fast Fourier transform technique to calculate the gravitational field anomalies on a flat Earth to infinity.

The equation for the Parker [19] algorithm is given as follows:

$\Delta g_{\text {topo }}(x)=F^{-1}\left\{2 \pi G\left(\rho_{\mathrm{c}}-\rho_{\mathrm{w}}\right) \mathrm{e}^{-k d} x \sum_{n=1}^{\infty} \frac{k^{n-1}}{n !} F\left\{h^{n}(x)\right\}\right\}$

where $F$ denotes Fourier transform, $F^{-1}$ denotes inverse Fourier transform, $h(x)$ is the topography, $G$ is the universal gravitational constant, $k$ is wavenumber (given by $2 \pi / \lambda$, where $\lambda$ is wavelength), $n$ is the number of terms and $d$ is the mean depth.
Fig. 3 Schematic illustration of the source of isostatic gravity anomaly

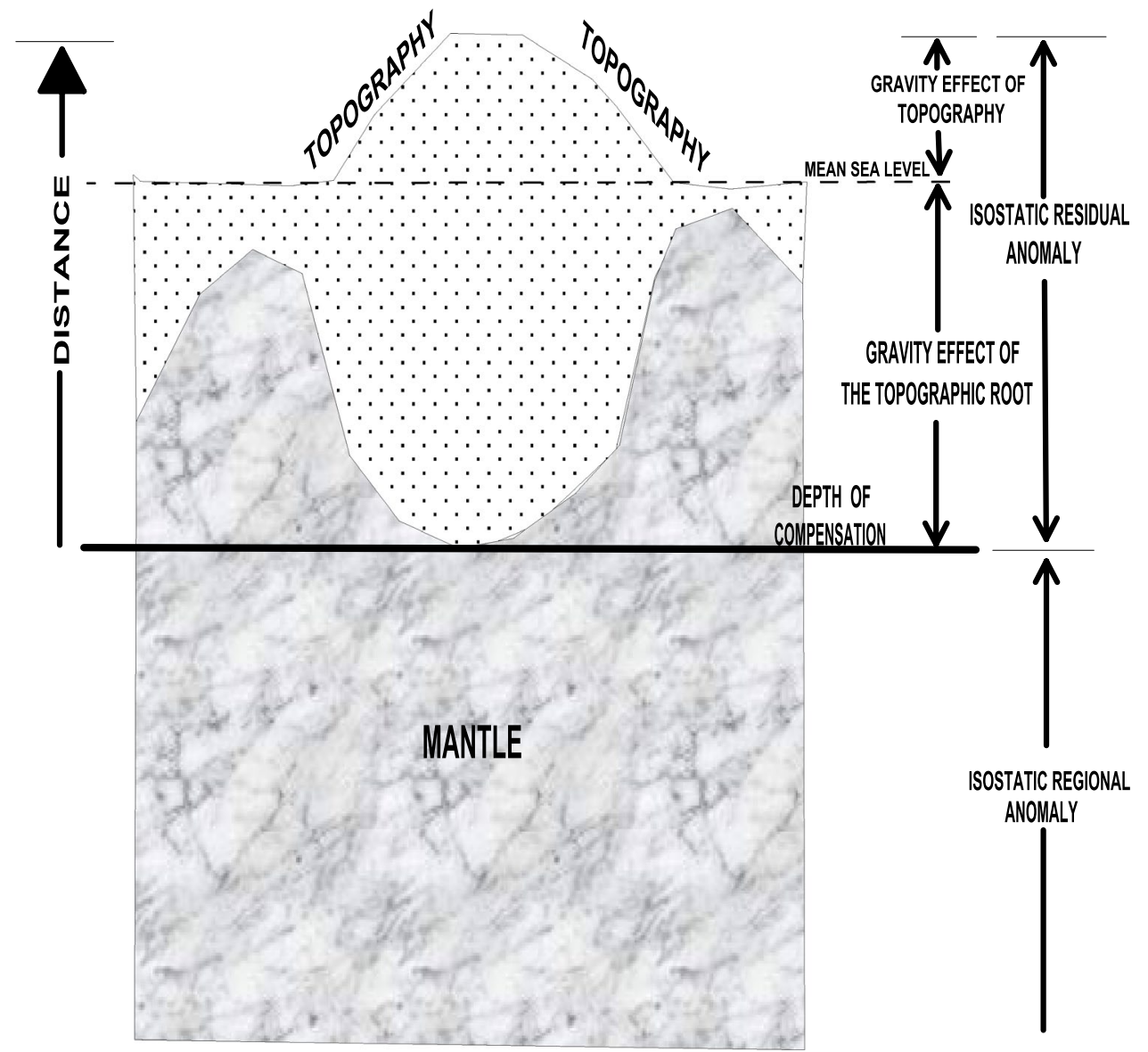


It was assumed that the effects of earth curvature are negligible and the flat Earth approximation is accurate since the distance (radius) of interest is limited to $166.7 \mathrm{~km}$. The AIRYROOT approach computes the near-field (isostatic residual) component which is the computed gravitational effect of compensating mass within a cylinder $166.7 \mathrm{~km}$ in radius based on a specified isostatic depth of compensation, topographic density and density contrast at depths. The gravitational field from $166.7 \mathrm{~km}$ out to infinity is then calculated by numerical integration of a Bessel function. The difference between these two calculations is the attraction of the root inside a cylinder of $166.7 \mathrm{~km}$ in radius [17].

\subsubsection{Isostatic overcompensation, undercompensation and normal compensation}

Figure 4 is the diagram depicting isostatic overcompensation, undercompensation and normal compensation. Isostatic overcompensation (when the topographic root is too large compared to the topography that it supports) is characterised with "negative computed gravity anomaly
$\left(\Delta g_{R}\right)$ of the root zone estimated from the topography, negative Bouguer gravity anomaly $\left(\Delta g_{\mathrm{B}}\right)$ and negative isostatic gravity anomaly $\left(\Delta g_{1}\right)$, with $\Delta g_{\mathrm{B}}$ more negative than $\Delta g_{R}{ }^{\prime \prime}$.

Isostatic undercompensation (when the topographic root is too small compared to the topography being supported) is characterised with "negative computed anomaly $\left(\Delta g_{R}\right)$ of the root zone estimated from the topography, negative Bouguer gravity anomaly $\left(\Delta g_{\mathrm{B}}\right)$ and positive isostatic gravity anomaly $\left(\Delta g_{\mathrm{i}}\right)$, with $\Delta g_{\mathrm{R}}$ more negative than $\Delta g_{\mathrm{B}}{ }^{\prime \prime}$.

For normal compensation, Bouguer gravity anomaly $\left(\Delta g_{\mathrm{B}}\right)$ equals computed gravity anomaly of the root zone $\left(\Delta g_{\mathrm{R}}\right)$, such that $\Delta g_{\mathrm{i}}=0$.

The continental region of the study area can be said to be made up of two sections with widely differing topographies: the western section which can be said to be of lower elevation (with mean elevation of $270 \mathrm{~m}$ ) and the eastern section which can be said to be of much higher elevation (with mean elevation of 1000 m) (Fig. 1). From the spectral analysis of the gravity data of the study area,
Fig. 4 Explanation of the isostatic gravity anomaly $\left(\Delta g_{1}\right)$ as the difference between the Bouguer gravity anomaly $\left(\Delta g_{\mathrm{B}}\right)$ and the computed anomaly $\left(\Delta g_{\mathrm{R}}\right)$ of the root zone estimated from the topography for a complete isostatic compensation, $\mathbf{b}$ isostatic overcompensation and c normal isostatic undercompensation (after [3])
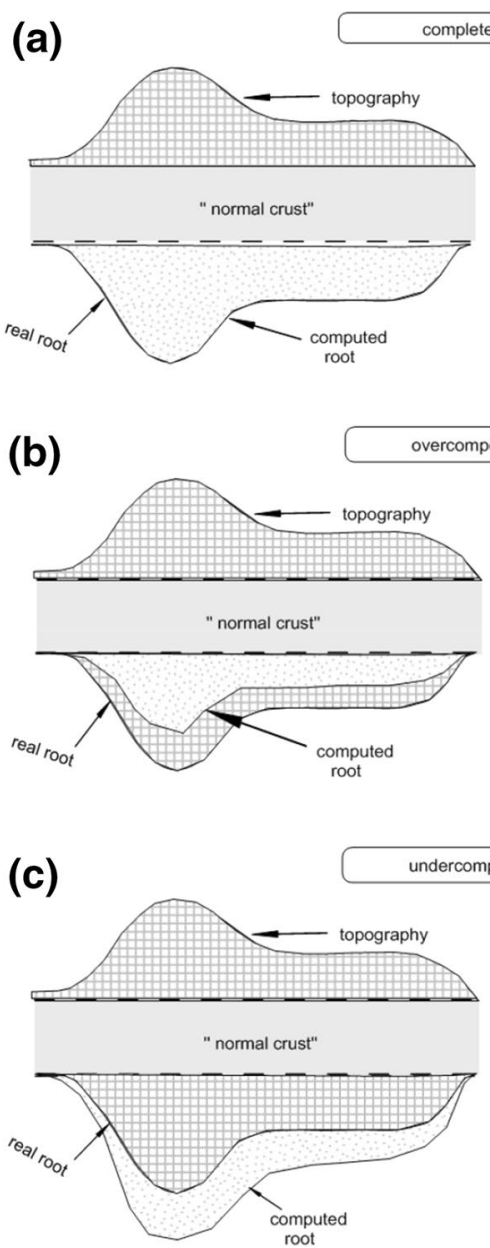
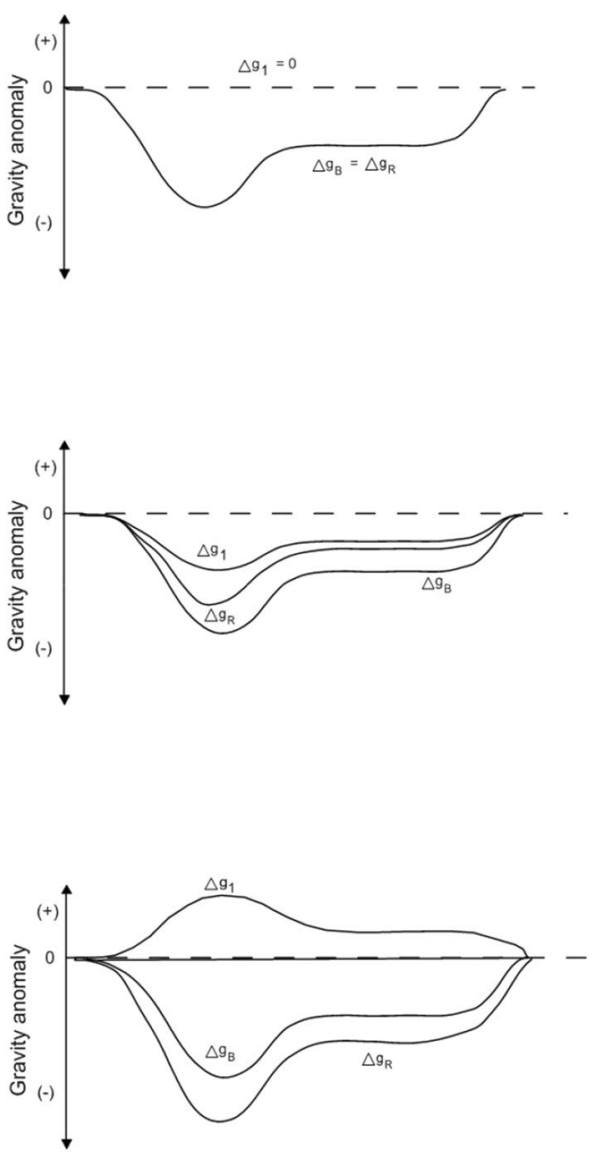
the average crustal thickness of the lower elevation western section is $31 \mathrm{~km}$ and the average crustal thickness at the eastern region of higher elevation is $34 \mathrm{~km}$ [20]. These crustal thicknesses agree with that given by Globig in the region around the Cameroon Volcanic Line [21].

The value of the Bouguer density on the continent was set at $2670 \mathrm{~kg} \mathrm{~m}^{-3}$, Bouguer density at sea was set at $2800 \mathrm{~kg} \mathrm{~m}^{-3}$, Moho density contrast on land was set at $480 \mathrm{~kg} \mathrm{~m}^{-3}$ and Moho density contrast at sea was set at $450 \mathrm{~kg} \mathrm{~m}^{-3}$. Also, the crustal root needed to compensate the topography in this region will be proportional to the overlying topography by a factor of $\frac{2,670}{480}=5.56$ such that a $1 \mathrm{~km}$ topography will be compensated by a crustal root of $5.56 \mathrm{~km}$. Therefore, with an average elevation of $270 \mathrm{~m}$ $(0.27 \mathrm{~km})$ and crustal thickness of $31 \mathrm{~km}$ at the western section of the continental region, the depth of compensation was set at $32.77 \mathrm{~km}$ (i.e. $31 \mathrm{~km}$ crustal thickness $+0.27 \mathrm{~km}$ topographic height above sea level $+1.50 \mathrm{~km}$ compensating root).

At the eastern section, the average elevation is $1 \mathrm{~km}$ and crustal thickness is $34 \mathrm{~km}$. The depth of compensation was set at $40.56 \mathrm{~km}$ (i.e. $34 \mathrm{~km}$ crustal thickness $+1 \mathrm{~km}$ topographic height above sea level $+5.56 \mathrm{~km}$ compensating root).

\subsection{Limitation of the study}

This work is a preliminary interpretation of the isostatic residual gravity anomaly for the region using a local model of isostatic compensation (Airy's model) which assumes that topographic features are fully compensated by crustal thicknesses variation. While new concepts in isostatic anomaly computation now favour the use of the flexural model (which incorporates the role of lithospheric mantle in isostatic compensation rather than just assuming that topographic features are fully compensated by crustal thicknesses variation), it is, however, a good starting point (starting with the Airy's model) as it can reveal the isostatic condition within the region to a good approximation.

Also, the computation of isostatic anomalies using Airy's model is based on the assumption of a uniform density crust floating on a heavier mantle material. While this assumption is flawed due to the fact that the crust is usually structurally and compositionally heterogeneous and heterogeneous structures may need different density/ density contrast values for them to be excellently resolved, underestimated or overestimated densities (or density contrasts) usually still reveal good number of isostatic anomalies though some of these anomalies might be masked or obliterated. However, in quantitative isostatic analysis studies, intracrustal density variations have major influence on the results. The limitation of the assumption of uniform crustal density associated with Airy's model would therefore inhibit highly quantitative interpretation in this study.

Finally, it should be noted that at present continuously operated/recorded GPS data are not fully available for the study area as Continuously Operating GPS Reference Stations are just being set up around this region. So, the predicted vertical crustal movement could not be corroborated with GPS data. This study is therefore not presented as a perfect or foolproof study but rather a pioneer isostatic work within the study area for the purpose of stimulating the interest and curiosity of more researchers who would integrate more geophysical methods and adopt a more representative isostatic model.

\section{Results and interpretation}

The Bouguer gravity, the root zone gravity and the isostatic residual gravity anomaly maps of the study area are presented in Figs. 5, 6 and 7, respectively.

An overview of the Airy's isostatic residual gravity anomaly map (Fig. 7) shows three distinct regions. The south-western portion (blue colouration) is characterised by negative isostatic residual gravity anomaly values, the eastern portion (pink colouration) is characterised by positive isostatic residual gravity anomaly values, and the central portion (green colouration) is characterised by isostatic residual gravity anomaly values that approach zero. Negative values ( -11 to $-200 \mathrm{mGal}$ ) were associated with the oceanic region, positive values $(+10$ to $+90 \mathrm{mGal})$ with the volcano-dominated eastern region, and zero value and values close to zero $(-10$ to $+9 \mathrm{mGal}$ ) were associated with the sedimentary basins within the study area. For detailed interpretation, profiles were taken in the north-south and east-west directions on the Airy's isostatic gravity anomaly map and were interpreted.

\subsection{The interpretation of the isostatic residual gravity anomaly profiles}

\subsubsection{Profile A-A': Fig. 8a}

The southern region consisting of the oceanic part and the continental shelf is isostatically overcompensated, while the continental part (northern region) is in isostatic equilibrium. Overcompensation occurs when the root is too large compared to the topography it supports. In terms of vertical crustal movement, overcompensation arises when part of the overlying topography has been eroded. This phenomenon usually results in vertical crustal uplift eventually. The continental part of the profile is in isostatic equilibrium. 


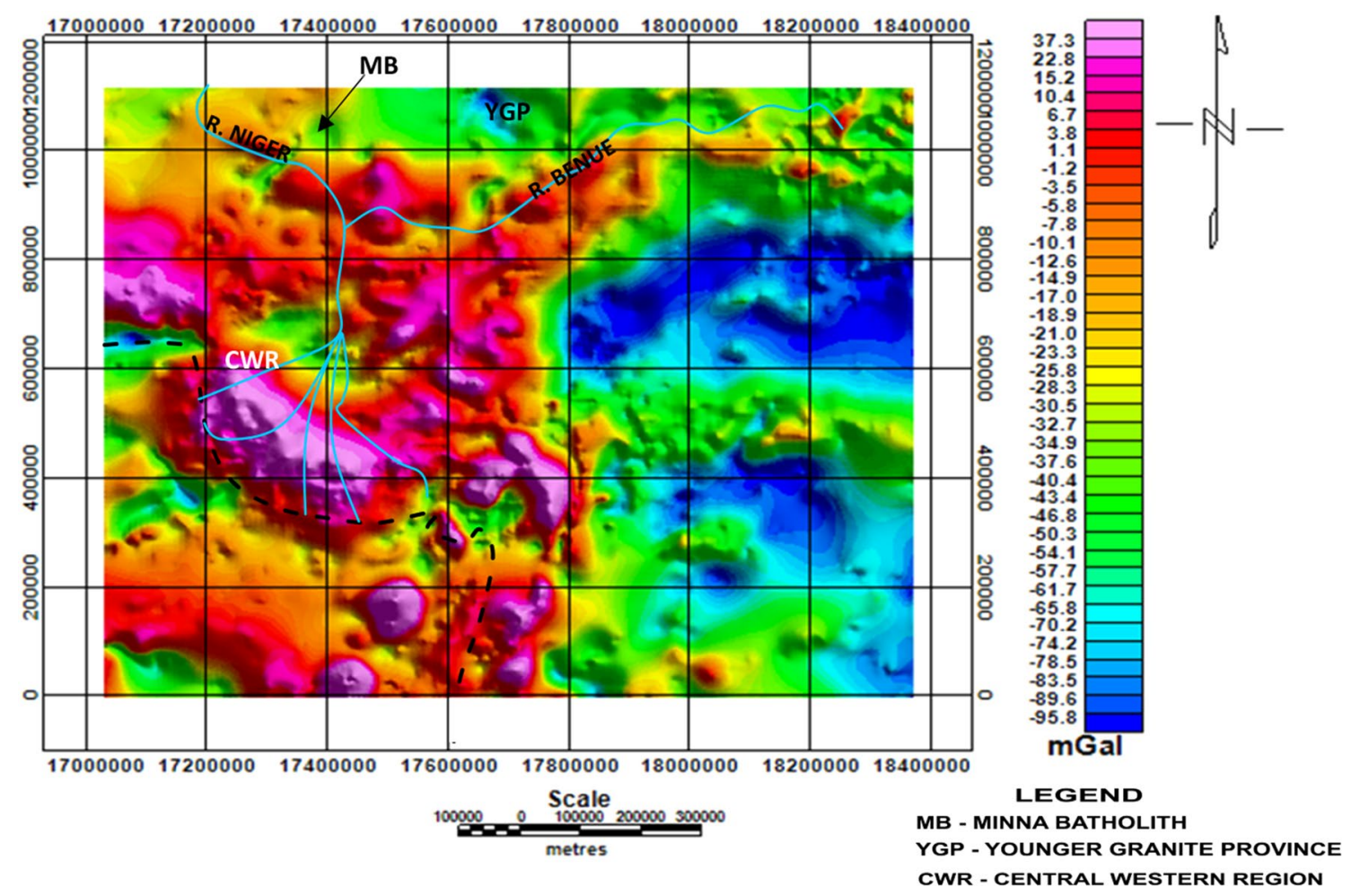

Fig. 5 Bouguer anomaly map of the study area

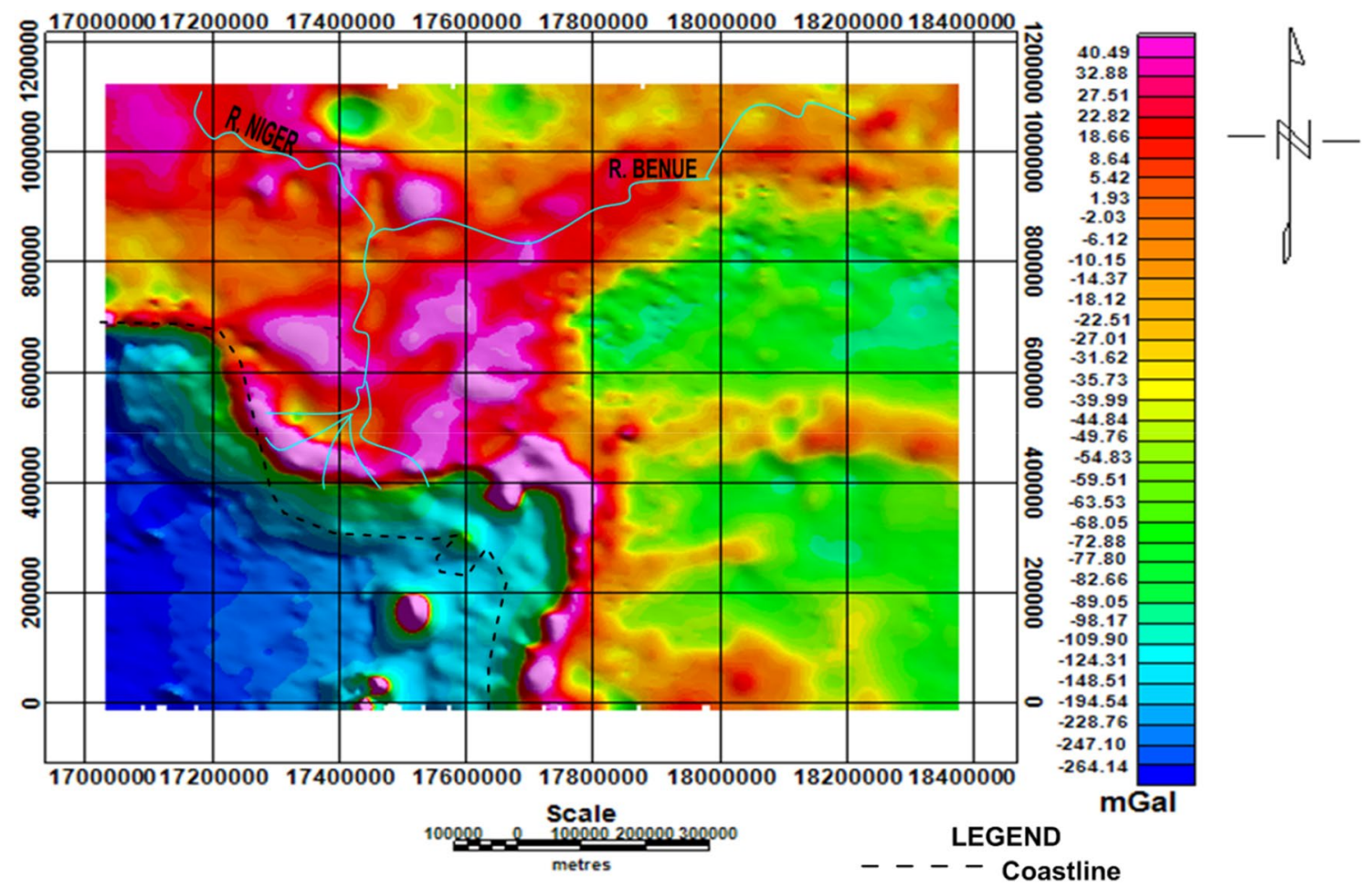

Fig. 6 Root zone anomaly map of the study area

SN Applied Sciences

a SPRINGER NATURE journal 

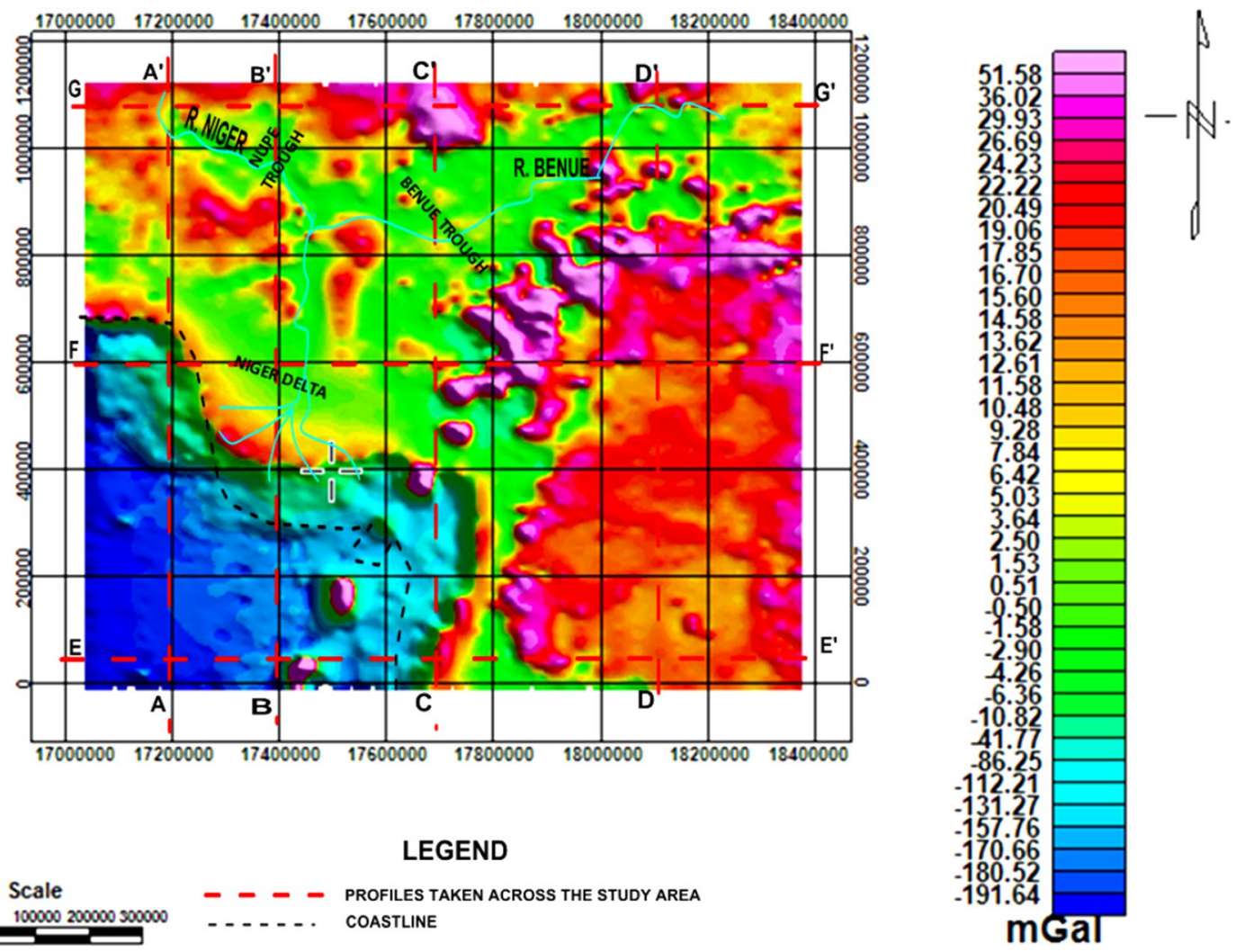

Fig. 7 Airy's isostatic residual gravity anomaly map of the study area

\subsubsection{Profile B-B': Fig. 8b}

The southern region consisting of the oceanic part and the continental shelf is isostatically overcompensated just like in Fig. 8a, and the continental part is in isostatic equilibrium. However, there is slight undercompensation at the northern terminal edge of the profile which corresponds with the boundary between the Mid-Niger (Bida) Trough and the Minna batholith. This undercompensation suggests that there may have been isostatic subsidence in the region and that further slight subsidence is imminent with time around this undercompensated region. Undercompensation occurs when crustal root is too small compared to the topography it supports. In terms of vertical crustal movement, undercompensation arises when tectonic forces thrust crustal blocks on top of each other or due to sediment loading. This phenomenon usually results in crustal subsidence eventually. Most of the continental part in this region has attained isostatic equilibrium. As revealed on the isostatic anomaly profile, the Niger Delta and most parts of the Mid-Niger (Bida) Trough are in isostatic equilibrium.

\subsubsection{Profile C-C': Fig. 8c}

Just like the preceding profiles, the southern region consisting of the oceanic part and the continental shelf is isostatically overcompensated, while the continental part (Calabar flank, Anambra Basin and Benue Trough) is in isostatic equilibrium. However, there is observable undercompensation at the northern terminal edge of the profile which corresponds to the Younger Granite Province of Jos. With this undercompensation, one could predict an imminent subsidence of some vertical column of the Jos Plateau. Vertical uplift is expected in the oceanic part which is currently overcompensated.

\subsubsection{Profile D-D': Fig. 8d}

The whole line is along a purely continental region. The elevation along the line is in excess of $500 \mathrm{~m}$ above sea level for most of its part. Most of this profile is isostatically undercompensated with only the northern end attaining isostatic equilibrium. Since most part of the line is undercompensated, the region is expected to subside with time. 

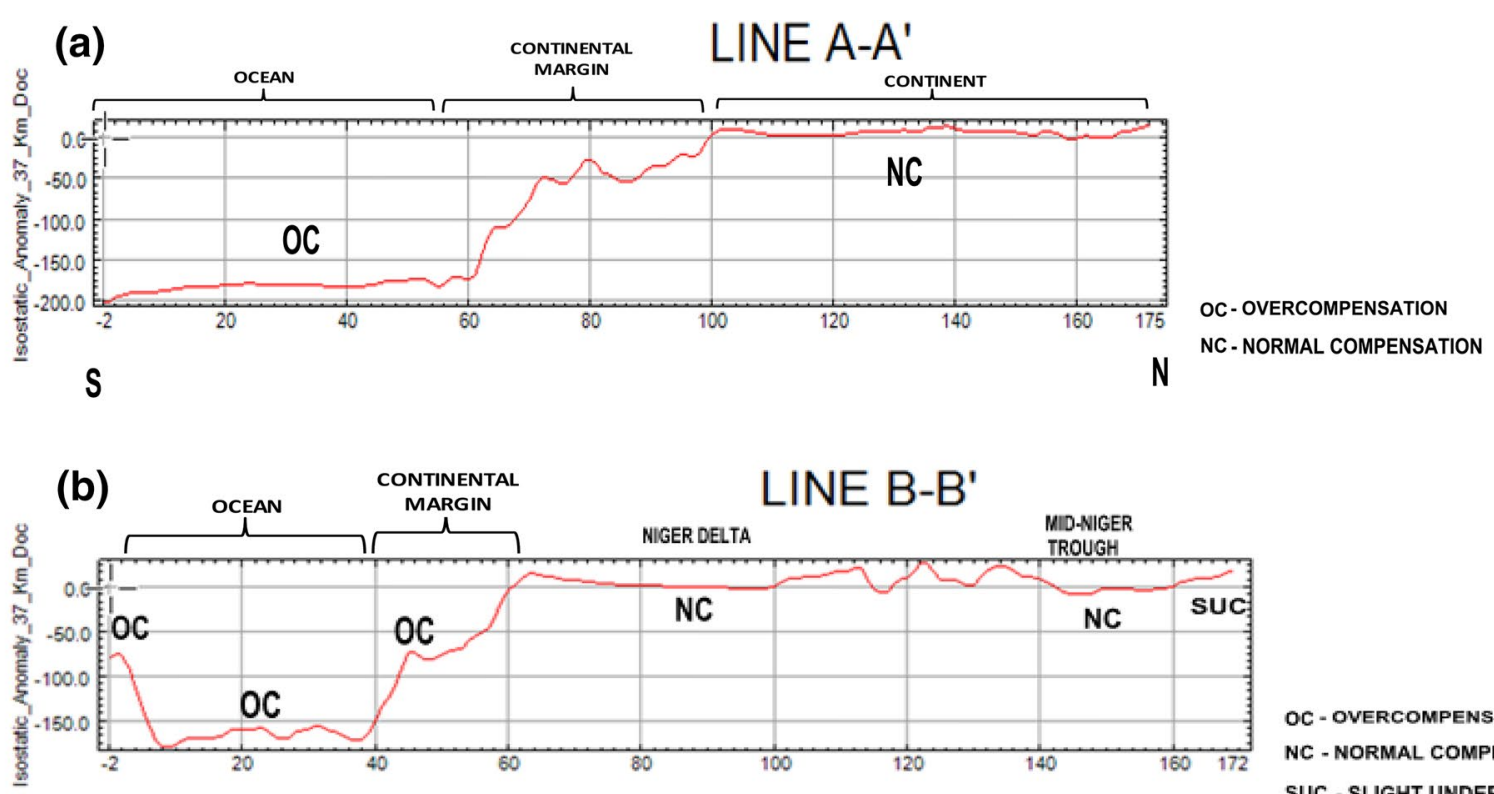

OC - OVERCOMPENSATION NC - NORMAL COMPENSATION S

$\mathbf{N}$ SUC - SLIGHT UNDERCOMPENSATION

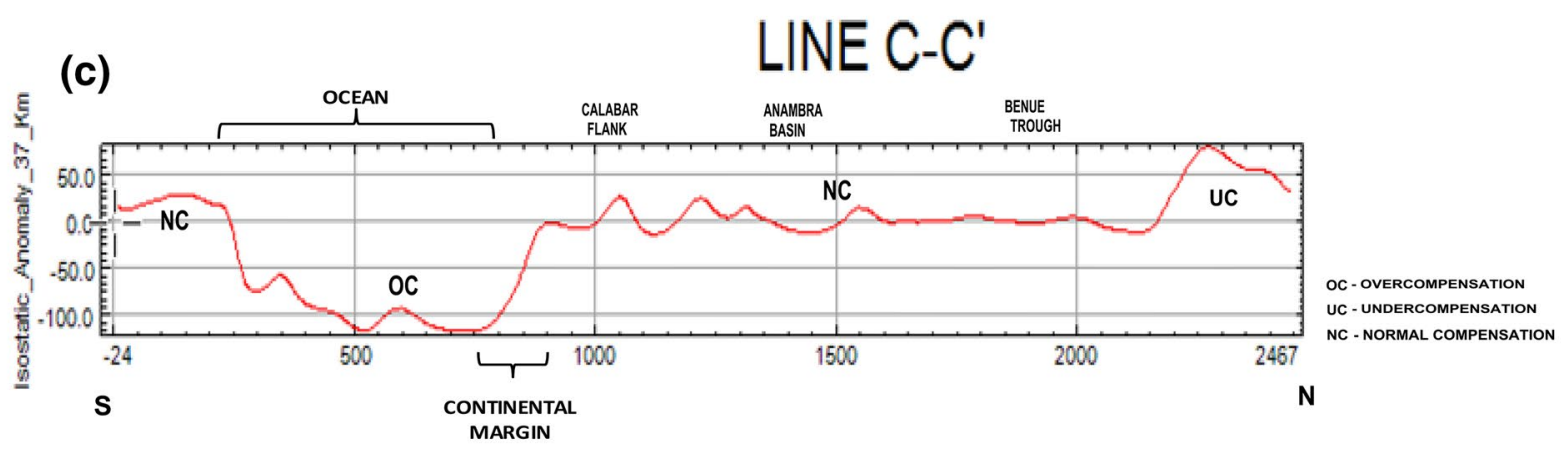

(d)

LINE D-D'

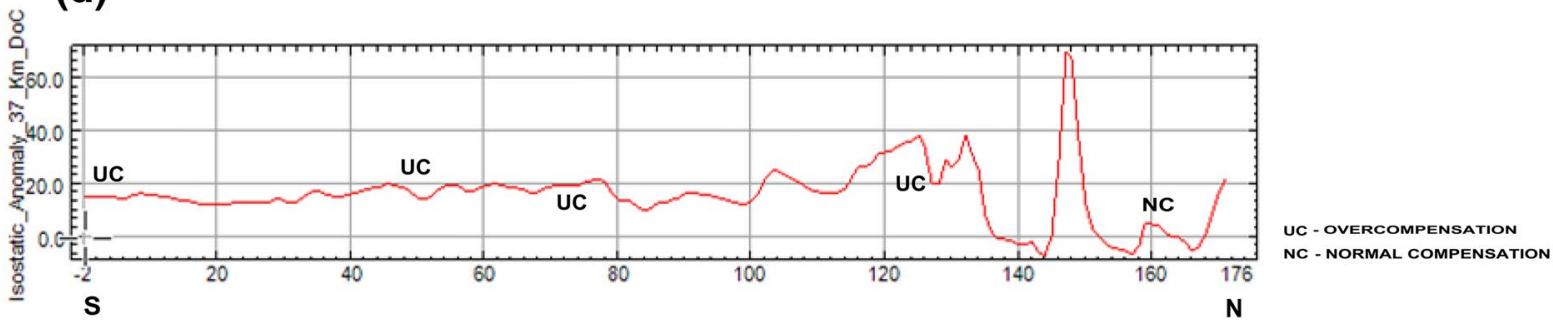

Fig. 8 a The isostatic anomaly profile along 17,200,000 mE (i.e. longitude $\left.4.51^{\circ} \mathrm{E}\right)$. b The isostatic anomaly profile along $17,400,000 \mathrm{mE}$ (i.e. longitude $6.30^{\circ} \mathrm{E}$ ). c The isostatic anomaly profile along $17,700,000 \mathrm{mE}$ (i.e. longitude $9.0^{\circ} \mathrm{E}$ ). d The isostatic anomaly profile

\subsubsection{Profile E-E': Fig. 8e}

This is an east-west trending profile along latitude $0.45^{\circ} \mathrm{N}$. The western half of it is within the oceanic region, and the other half (eastern part) is within the continental region. The oceanic region is isostatically overcompensated, and the continental region is in along $18,120,000 \mathrm{mE}$ (i.e. longitude $12.8^{\circ} \mathrm{E}$ ). e The isostatic anomaly profile along $50,000 \mathrm{mN}$ (i.e. latitude $0.45^{\circ} \mathrm{N}$ ). $\mathbf{f}$ The isostatic anomaly profile along $600,000 \mathrm{mN}$ (i.e. latitude $5.4^{\circ} \mathrm{N}$ ). g The isostatic anomaly profile along $1,100,000 \mathrm{mN}$ (i.e. latitude $10.0^{\circ} \mathrm{N}$ )

isostatic equilibrium. However, the Sao Tome Island that occurred within the oceanic region is isostatically undercompensated. Vertical uplift is expected in the isostatically overcompensated oceanic region, and vertical subsidence is expected on the Sao Tome Island. The probable reason for isostatic undercompensation on the Sao Tome Island is either due to thrusting of the 

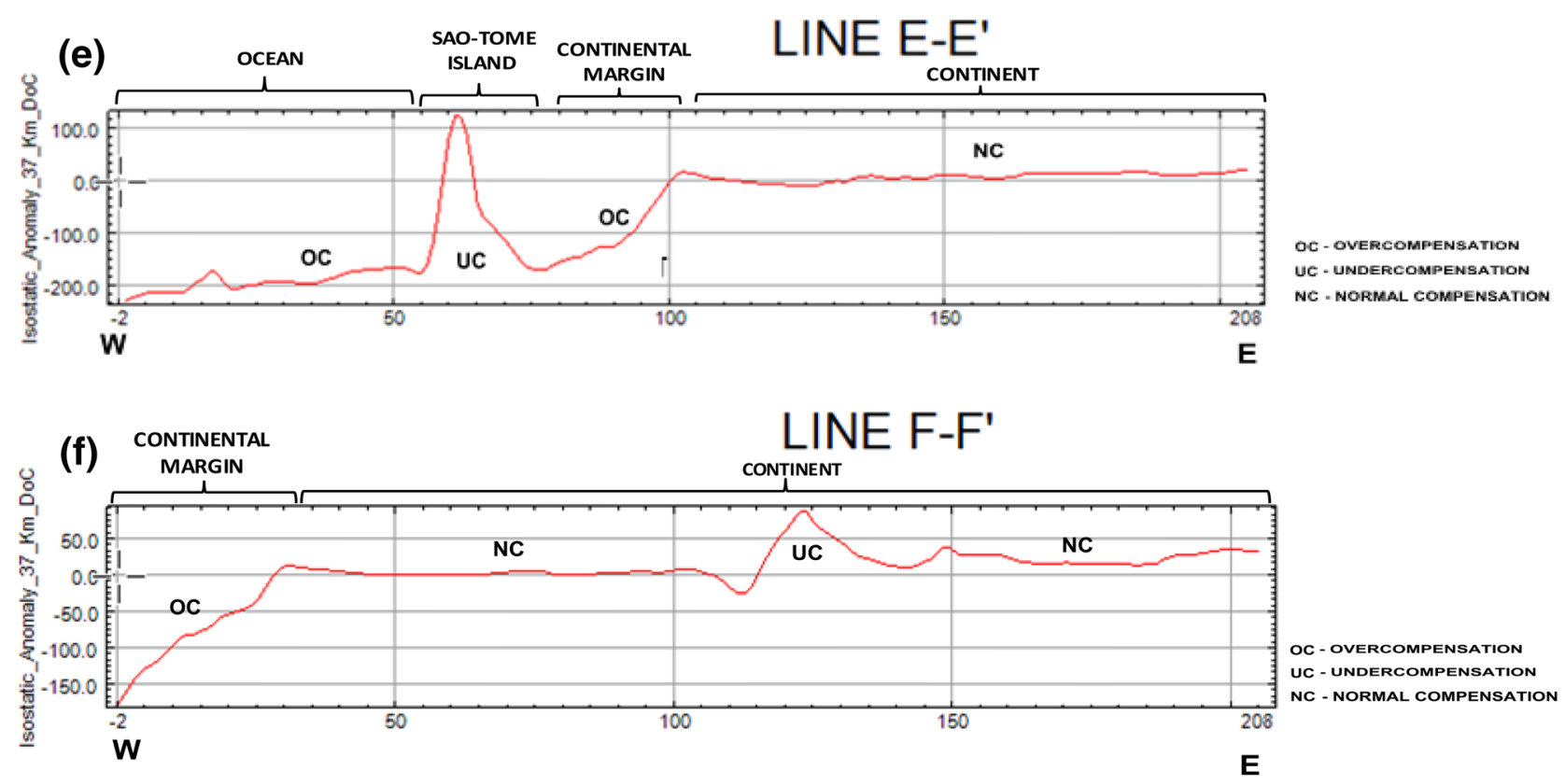

\section{(g)}

\section{LINE G-G'}

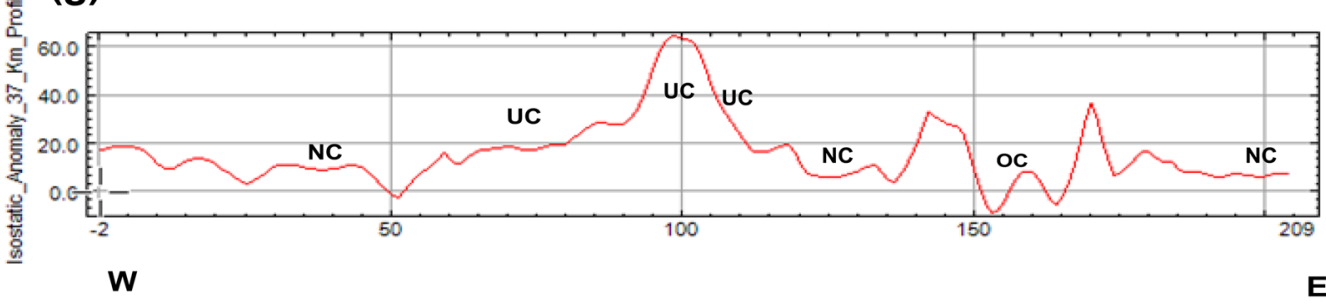

OC - OVERCOMPENSATION UC - UNDERCOMPENSATION NC - NORMAL COMPENSATION

Fig. 8 (continued)

crustal block on each other due to tectonic forces, the region being an active tectonic region, or the relative youngness of the volcano making up the island itself which is not older than 15.7 Ma [22], which constitute a sort of lithospheric load that may not have attained isostatic equilibrium. The undercompensation could also be due to the combination of both factors.

\subsubsection{Profile F-F': Fig. $8 f$}

This is also an east-west running profile. The westernmost, continental margin part of the profile is overcompensated. The remaining part is a continental region and is in isostatic equilibrium. However, there is the Manengouba Volcano where there is isostatic undercompensation. With time, vertical crustal upliftment is imminent in the oceanic region, while subsidence is imminent on the undercompensated Manengouba Volcano of Cameroon.

\subsubsection{Profile G-G': Fig. 8g}

The whole profile is along a purely continental region. The westernmost part is part of the south-western basement complex of Nigeria. It is in isostatic equilibrium. The central portion of the profile is isostatically undercompensated. This central area spans from Zungeru (Niger State, Nigeria) to Kumo (Gombe State, Nigeria). The area is an upland. Due to its isostatic undercompensation, subsidence is likely to occur in this area over time. The eastern part of the profile corresponds with Mandara Volcano area. Most of this part is in isostatic equilibrium.

\section{Conclusion}

General Geodynamic Inferences from the Isostatic Analysis:

1. The oceanic part of the study area is characterised by isostatic overcompensation. Isostatic overcompensa- 
tion is usually associated with topographic erosion and usually results in vertical crustal uplift. In the study area, the topographic erosion that is plausible in this oceanic region is continuous seafloor spreading which can be synonymous with oceanic topographic erosion. The bathymetry in this area is expected to become shallower with time in response to this process.

2. Isostatic equilibrium is a proof of geodynamic stability in terms of vertical crustal movement. Seafloor spreading in the oceanic region of the study area seems to be a form of topographic erosion that was depicted by the isostatic overcompensation observed in the oceanic area. This spreading is observed to effectively terminate on the continental shelf as isostatic equilibrium is achieved as we moved into the continental areas from this shelf. The continental shelf therefore represents the terminal extent to which the seafloor spreading is noticeably active. This is consistent with the interpretation of the sub-crustal mantle density map within the study area [23] which identifies areas beyond the continental shelf landward as areas where the mantle density gradient is smaller than required to keep driving the seafloor spreading.

3 Having been restricted at the continental shelf, the checked seafloor spreading, emanating from the west (oceanic region) and whose direction of spreading has been towards the east (continental shelf), may have likely resulted in thrust tectonics in the region of the Sao Tome Island and thus contribute to the isostatic undercompensation associated with the island and probably the other islands of the oceanic section of the Cameroon Volcanic Line (CVL).

4 Most Nigerian sedimentary basins (Niger Delta, MidNiger (Nupe) Trough, Benue Trough, Anambra Basin and Calabar Flank) are in isostatic equilibrium or near isostatic equilibrium.

5 Most of the inland volcanoes in the study area are still isostatically undercompensated and so vertical subsidence of the volcanoes is still expected.

6 The relief (topography/bathymetry) conforming behaviour of the isostatic anomaly profiles (around the continental shelf, within the oceanic region and in the Younger Granites Province) suggests that the flexural isostatic model is likely to approximate the study area better than the Airy's model which was adopted.

\section{Recommendation}

As highlighted under the limitations of the study, this study is not presented as a perfect study but rather a pioneer isostatic work within the study area for the purpose of stimulating the interest and curiosity of more researchers who would integrate more geophysical methods and adopt a more representative isostatic model. Therefore, it is recommended that isostatic anomalies be recomputed using the flexural isostatic model.

Finally, it should be noted that though in computing the isostatic anomalies the model used in this study assumed a homogeneous oceanic crustal density of $2800 \mathrm{~kg} \mathrm{~m}^{-3}$ and a homogeneous continental crustal density of $2670 \mathrm{~kg} \mathrm{~m}^{-3}$, the continental crustal densities would be heterogeneous in most cases, containing high-velocity/ high-density lower crustal bodies, middle/upper crustal magmatic intrusions, low-density granites and other compositional heterogeneities. It is therefore recommended that intracrustal density anomalies (derivable from seismic data) be put into consideration when following up this study with a more detailed study.

Acknowledgements The author is grateful to the University of Leeds Industrial Service Ltd., Leeds, UK, and Scripps Institution of Oceanography, University of California, San Diego, USA, for making the data available.

\section{Compliance with ethical standards}

Conflict of interest On behalf of all authors, the corresponding author states that there is no conflict of interest.

\section{References}

1. Bowie W (1927) Isostasy: the science of the equilibrium of the earth's crust. E.P. Dutton, New York

2. Watts AB (2007) An overview. In: Schubert G (ed) Treatise on geophysics: crust and lithosphere dynamics. Elsevier, Amsterdam, pp 1-48

3. Lowrie W (1997) Fundamentals of geophysics. Cambridge University Press, Cambridge

4. Elsheikh AA, Gao SS, Liu KH (2014) Formation of the Cameroun Volcanic line by Lithospheric Basal Erosion: insight from mantle seismic anisotropy. J Afr Earth Sci 100:96-108

5. Machens E (1973) The geological history of the marginal basins along the north shore of the Gulf of Guinea. In: Nairn AEM, Stehli FG (eds) The Ocean basins and margins-The South Atlantic. Plenum Press, New York, pp 351-390

6. Burke K, Dewey JF (1974) Two plates in Africa during the cretaceous. Nat Geosci 249:313-316

7. Nwajide CS (1990) Sedimentation and paleogeography of the central benue trough, Nigeria. In: Ofoegbu CO (ed) The benue trough structure and evolution. Vieweg, Braunschweig, pp 19-38

8. Hoffman P, Dewey JF, Burke K (1974) Aulacogens and their genetic relation to geosynclines with a proterozoic example from great Slave lake, Canada. In: Dott R, Shaver R (eds) Modern and ancient geosynclinal sedimentation (SP19). The society of economic paleontologists and mineralogists (SPEM), Special Publication, pp 38-55

9. Olade MA (1975) Evolution of Nigeria's benue trough (aulacogen): a tectonical model. Geol Mag 112(06):575-583

10. Petters SW (1978) Stratigraphic Evolution of the benue trough and its implications for the upper cretaceous paleogeography of West Africa. J Geol 86(May 1):311-322 
11. Osazuwa IB (1978) Gravity and magnetic survey of upper benue trough. Ahmadu Bello University, Zaria

12. Adeleye DR (1974) Sedimentology of the fluvial bida sandstones (cretaceous) Nigeria. Sediment Geol 12(1):1-24

13. Ojo SB, Ajakaiye DE (1976) Preliminary interpretation of gravity measurements in the middle Niger Basin area, Nigeria. In: Kogbe CA (ed) Geology of Nigeria. Elizabethan Publishing Co., Lagos, pp 295-307

14. Doust H, Omatsola E (1990) Niger Delta. In: Edwards JD, Santogrossi PA (eds) Divergent/passive Margin Basins. American Association of Petroleum Geologists, Tulsa, pp 239-248

15. Nnange JM et al (2000) Depths to density discontinuities beneath the Adamawa Plateau region, Central Africa, from spectral analyses of new and existing gravity data. J Afr Earth Sci 30(4):887-901

16. Ngako V, Affaton P, Njonfang E (2008) Pan-African tectonics in Northwestern Cameroon: implication for the history of western Gondwana. Gondwana Res 14:509-522

17. Heywood CE (1992) Isostatic residual gravity anomalies of New Mexico. In: Water-resources investigations report, United States Geological Survey

18. Simpson RW, Jachens RC, Blakely RJ (1983) AIRYROOT: a FORTRAN program for calculating the gravitational attraction of an airy isostatic root out to 166.7 Kilometers. In: U.S. geological survey open-file report 1983, United States Geological Survey, p 66

19. Parker RL (1972) The rapid calculation of potential anomalies. Geophys J R Astron Soc 31:447-455

20. Balogun OB, Ojo SB (2016) A study of the tectonic processes in the central portion of the equatorial Atlantic African region derived from mantle density analysis. J Min Geol 52(2):201-215

21. Globig J, Fernandez M, Torne M, Verges J, Robert A, Faccenna $C$ (2016) New insights into the crust and lithospheric mantle structure of africa from elevation, geoid and thermal analysis. J Geophys Res Solid Earth 121:5389-5424

22. Deruelle B et al (1990) The Cameroon line: a review. In: Kampunzu AB, Lubala RT (eds) Magmatism in extensional structural settings. Springer, Berlin, pp 274-327

23. Balogun $\mathrm{OB}$ (2015) A study of the tectonic processes in the niger delta and adjacent regions as derived from mantle density and isostatic analyses. Obafemi Awolowo University, Ile-Ife, p 174

Publisher's Note Springer Nature remains neutral with regard to jurisdictional claims in published maps and institutional affiliations. 